\title{
Boas práticas de ordenha para redução da contaminação microbiológica do leite no agreste Pernambucano
}

\section{Good practices in milking to reduce microbiological contamination of milk in agreste of Pernambuco}

\author{
Marcelo Takeo Matsubara ${ }^{1}$; Vanerli Beloti ${ }^{*}$; Ronaldo Tamanini ${ }^{1}$; Rafael Fagnani ${ }^{3}$; \\ Livia Cavaletti Corrêa da Silva'; Alexandre Amorim Monteiro'; ${ }^{1}$ Ana Paula Pavão

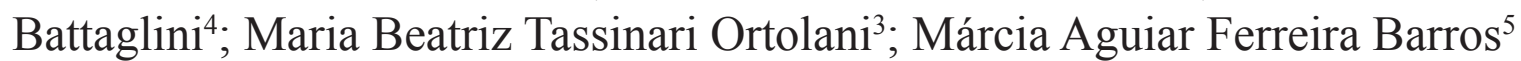

\section{Resumo}

Em Pernambuco, assim como na maior parte do país, o leite, sobretudo nas pequenas propriedades, é obtido em precárias condições higiênicas, com pouca tecnologia e deficiente controle sanitário dos animais. O leite cru apresenta baixa qualidade microbiológica, o que compromete a composição do produto, reduz sua vida de prateleira e pode constituir risco à saúde pública. A qualidade e a segurança dos alimentos estão associadas às boas práticas de produção (BPP). A implantação das BPP resulta na redução do número de microrganismos do leite levando a uma melhor qualidade microbiológica e maior vida de prateleira do produto final. O objetivo deste trabalho foi avaliar o impacto da implantação de boas práticas de ordenha na melhoria da qualidade microbiológica do leite, visando atingir os padrões estabelecidos pela Instrução Normativa 51. Foram aplicadas diferentes práticas de ordenha nos principais pontos de contaminação, identificados previamente, em quatro propriedades do Agreste Pernambucano. As práticas foram avaliadas através da enumeração de microrganismos indicadores aeróbios mesófilos, psicrotróficos, estafilococos coagulase positivos, coliformes totais e Escherichia coli antes e após aplicação das práticas. As práticas adotadas foram: desprezo dos três primeiros jatos de leite, imersão dos tetos em solução clorada, higienização vigorosa e posterior inversão dos latões e baldes para eliminação da água residual. Os resultados demonstram com aplicação das práticas redução média de 99,9\% de microrganismos aeróbios mesófilos no leite. As práticas indicadas são simples, eficientes, de fácil incorporação na rotina da ordenha em qualquer situação de tecnificação das propriedades e não requerem gastos com instalações.

Palavras-chave: Produção leiteira, melhoria da qualidade, microrganismos indicadores

\author{
Abstract \\ In Pernambuco, as well as in the major part of Brazil, milk, especially in small dairy farms, is obtained \\ in poor hygienic conditions, little technology and deficient sanitary control of animals. Raw milk \\ presents low microbiologic quality, which compromises the product's composition, reduces its shelf life \\ and can constitute risk to public health. Food quality and safety are related to the Good Manufacturing

\footnotetext{
${ }^{1}$ Programa de Pós-Graduação em Ciência Animal, DMVP, CCA, Universidade Estadual de Londrina, UEL, Londrina, PR. E-mail: lipoa.uel@gmail.com

${ }^{2}$ Prof ${ }^{a}$ do DMVP, CCA, UEL, Laboratório de Inspeção de Produtos de Origem Animal, LIPOA. Londrina, PR. E-mail: neli@, sercomtel.com.br; lipoa.uel@gmail.com

${ }^{3}$ Iniciação Científica do Curso de Medicina Veterinária,LIPOA, UEL, Londrina-PR. E-mail: rafaelfagnani@hotmail.com; maria. ortolani@br.nestle.com

${ }^{4}$ Residente do LIPOA, DMVP, CCA, UEL. E-mail: apaulabattaglini@hotmail.com

${ }^{5}$ Técnica de nível superior do LIPOA, DMVP, CCA, UEL. E-mail: mafer@unb.br

* Autor para correspondência
} 
Pratices (GMP). Implementation of GMP results in reduction of the number of microorganisms in milk, leading to a better microbiologic quality and enhanced shelf life of the final product. The aim of this work was to evaluate the impact of implementation of Good Milking Practices on the improvement of microbiological quality of milk, aiming to achieve the standards established by Normative Instruction 51. Different practices of milking were applied in the main points of contamination, identified previously, in four dairy farms of Agreste of Pernambuco. The practices were evaluated through enumeration of indicator microorganisms mesophilic aerobes, psychrotrophics, coagulase positive staphylococci, total coliforms and Escherichia coli before and after the application of the practices. The practices adopted were: elimination of first three jets of milk, immersion of teats in chlorinated solution, vigorous cleaning and posterior inversion of buckets and cans for elimination of residual water. Results showed, with the application of the practices, means reduction of $99.9 \%$ for mesophilic aerobes microorganisms. The practices indicated are simple, efficient, of easy adoption in milking routine in any situation of technology at the dairy farms and do not require spends with installations.

Key words: Milk production, quality improvement, indicator microorganisms

\section{Introdução}

O agreste de Pernambuco é a região intermediária entre a zona da mata e o sertão e é caracterizada por uma economia diversificada, com o cultivo de lavouras como milho, feijão e mandioca, além da pecuária de leite e de corte (CONAB, 2004; FIGUEIROA, 2006).

A produção leiteira anual é de cerca de 360 milhões de litros, o que coloca Pernambuco como o segundo produtor do Nordeste. São cerca de 14 mil pequenos e médios produtores atuando no mercado estadual. A produção no inverno, época das chuvas, chega a 980 mil litros de leite/dia, enquanto no verão, cai para $850 \mathrm{mil}$ litros/dia (SPRRA, 2007).

Em 2000 foi lançado o Programa Leite de Pernambuco, uma parceria entre Governo Federal e Estadual, com o principal objetivo de comprar leite de pequenos produtores e fornecer a famílias carentes, especialmente crianças, gestantes e lactantes. Esse programa impulsionou a cadeia produtiva leiteira, incentivando a produção local e favorecendo principalmente as regiões do agreste, zona da mata e metropolitana do Recife (SPRRA, 2007).

Em Pernambuco, como na maior parte do país, predominam propriedades leiteiras onde o leite é obtido em precárias condições higiênicas na ordenha, com pouca tecnologia e deficiente controle sanitário dos animais. Predomina a ordenha manual com bezerro ao pé e quando mecânica, prevalece uso de sistema balde ao pé com a presença do bezerro (MONTEIRO et al., 2007). Nero et al. (2005) estudando o leite de 53 propriedades do agreste de Pernambuco, encontraram a média de 16,8 milhões de UFC/mL de aeróbios mesófilos no leite. Este leite apresenta baixa qualidade microbiológica, que compromete sua composição e durabilidade, e constitui um risco à saúde da população quando consumido sem tratamento térmico (CATÃO; CEBALLOS, 2001; MARTINS; ALBUQUERQUE, 1999; MONTEIRO, et al., 2007; PADILHA et al., 2001).

De maneira geral, a baixa qualidade do produto pode ser atribuída a deficiências no manejo, higiene de ordenha, sanidade da glândula mamária, manutenção e desinfecção inadequada dos equipamentos e refrigeração ineficiente ou até mesmo inexistente (FAGAN et al., 2005; NERO et al., 2005). Assim, cuidados higiênicos para evitar a contaminação do leite devem ter início na ordenha e seguir até o seu beneficiamento (CATÃO; CEBALLOS, 2001; SANTANA et al., 2001), por meio das boas práticas de produção e fabricação.

As boas práticas de produção (BPP) devem ser aplicadas desde a obtenção e durante o armazenamento e transporte da matéria-prima, que no caso da produção leiteira pode-se traduzir em higiene de ordenha, resfriamento e granelização. A implantação destas BPP resulta na redução do número 
de microrganismos da matéria prima, melhoria da sanidade da glândula mamária dos animais, que associadas às boas práticas no beneficiamento, levam a uma maior vida de prateleira do produto (NELSON, 1992).

Para avaliar a qualidade microbiológica do leite, utilizam-se os microrganismos indicadores de qualidade, sendo os mais importantes os aeróbios mesófilos (AM), estafilococos coagulase positivos (ECP), coliformes totais (CT) e Escherichia coli (EC) e, para o leite refrigerado, os psicrotróficos (PS). A detecção e enumeração destes microrganismos são de importância para a avaliação tanto da qualidade final do leite, como da eficiência de práticas de sanitização de equipamentos e utensílios, qualidade na manipulação do produto e fontes de contaminação durante a obtenção, transporte e beneficiamento do leite (BELOTI et al., 1997; BELMONTE; LAGO, 2004; FRANCO; LANDGRAF, 2008).
Este trabalho teve como objetivo avaliar o impacto da implantação de boas práticas de produção na melhoria da qualidade microbiológica do leite, utilizando microrganismos indicadores, visando atingir os padrões estabelecidos pela Instrução Normativa 51 (BRASIL, 2002).

\section{Material e Métodos}

Este trabalho foi realizado no período de agosto de 2005 a novembro de 2006, em quatro propriedades do agreste pernambucano, sendo duas no município de Bom Conselho e duas no município de São Bento do Una. Estas propriedades foram selecionadas por orientação da Secretaria da Produção Rural e Reforma Agrária (SPRRA, 2007) do Estado de Pernambuco, de forma a representar o perfil da produção regional, quanto aos aspectos de produção como condições das instalações e características de manejo. As características das propriedades e práticas de ordenha encontram-se no (Quadro 1).

Quadro 1. Características das quatro propriedades estudadas no agreste pernambucano no período de agosto de 2005 a novembro de 2006, nos municípios de Bom Conselho e São Bento do Una.

\begin{tabular}{|ccccc|}
\hline Características / Propriedades & P1 & P2 & P3 & P4 \\
\hline No de animais em lactação & 60 & 70 & 30 & 9 \\
Raça dos animais & mestiços & mestiços & mestiços & mestiços \\
N $^{\text {de ordenhas diárias }}$ & 2 & 2 & 2 & 2 \\
Produção média diária & $850 \mathrm{~L}$ & $800 \mathrm{~L}$ & $400 \mathrm{~L}$ & $27 \mathrm{~L}$ \\
Tipo de ordenha & Mecânica & manual & manual & manual \\
Presença de bezerro & balde ao pé & sim & sim & sim \\
Lavagem dos tetos & sim & não & não & não \\
Prática de pré-dipping & não & não & não & não \\
Prática de pós-dipping & $\operatorname{sim}^{1}$ & não & não & não \\
Higienização das teteiras & sim² & - & - & - \\
Despreza os 3 1 jos jatos & sim & não & não & não \\
Realiza CMT & sim & não & não & não \\
Piso impermeável na ordenha & não & não & sim & não \\
Instalação coberta & sim & não & não & não \\
Lavagem das mãos & sim & não & não & não \\
Fonte de água & lagoa & açude & açude & mina \\
Tratamento da água & cloro & nenhum & nenhum & nenhum \\
Resfria o leite & não & não & não & não \\
Recolhimento do leite & diário & diário & diário & diário \\
\hline
\end{tabular}

${ }^{1}$ pré-dipping somente nos animais sem bezerro ao pé, com solução iodada.

${ }^{2}$ pós-dipping com solução iodada. 


\section{Práticas propostas de higiene na ordenha}

A partir da identificação dos principais pontos de contaminação nestas mesmas propriedades realizada anteriormente em outro trabalho (BELOTI et al., 2006), implantou-se práticas focadas na redução da contaminação nestes pontos. Para estafilococos os principais pontos de contaminação foram: os três primeiros jatos, tetos, leite da cisterna do úbere e mãos do ordenhador. Para os demais microrganismos estudados os principais pontos de contaminação foram: água residual do latão, fundo do latão, resfriador, tetos, três primeiros jatos, teteiras, balde e mãos do ordenhador (BELOTI et al., 2006).

As práticas implantadas (Quadro 2) foram o desprezo dos três primeiros jatos de leite, imersão direta do teto em solução clorada 750 ppm em caneca sem refluxo, higienização vigorosa de latões e baldes com detergente alcalino clorado $2 \%$ e fibra macia LT Scotch-brite ${ }^{\mathrm{TM}}$ ou fibra vegetal. Inversão dos latões e baldes para eliminação da água residual. Para teteiras além da lavagem após o uso, com escova apropriada e detergente alcalino clorado, foi recomendado, imediatamente antes do uso, a imersão em solução clorada 750 ppm por 30 segundos, seguida de enxágüe em água também por imersão. Cada uma destas práticas foi previamente estudada isoladamente, para acertos dos princípios e concentrações recomendados (FAGAN et al., 2005). Este trabalho mostra as práticas que apresentaram maior eficiência na diminuição da contaminação e maior impacto na qualidade microbiológica.

Quadro 2. Práticas modificadas a partir de Fagan et al. (2005), aplicadas em quatro propriedades leiteiras no período de agosto de 2005 a novembro de 2006, nos municípios de Bom Conselho e São Bento do Una, em Pernambuco.

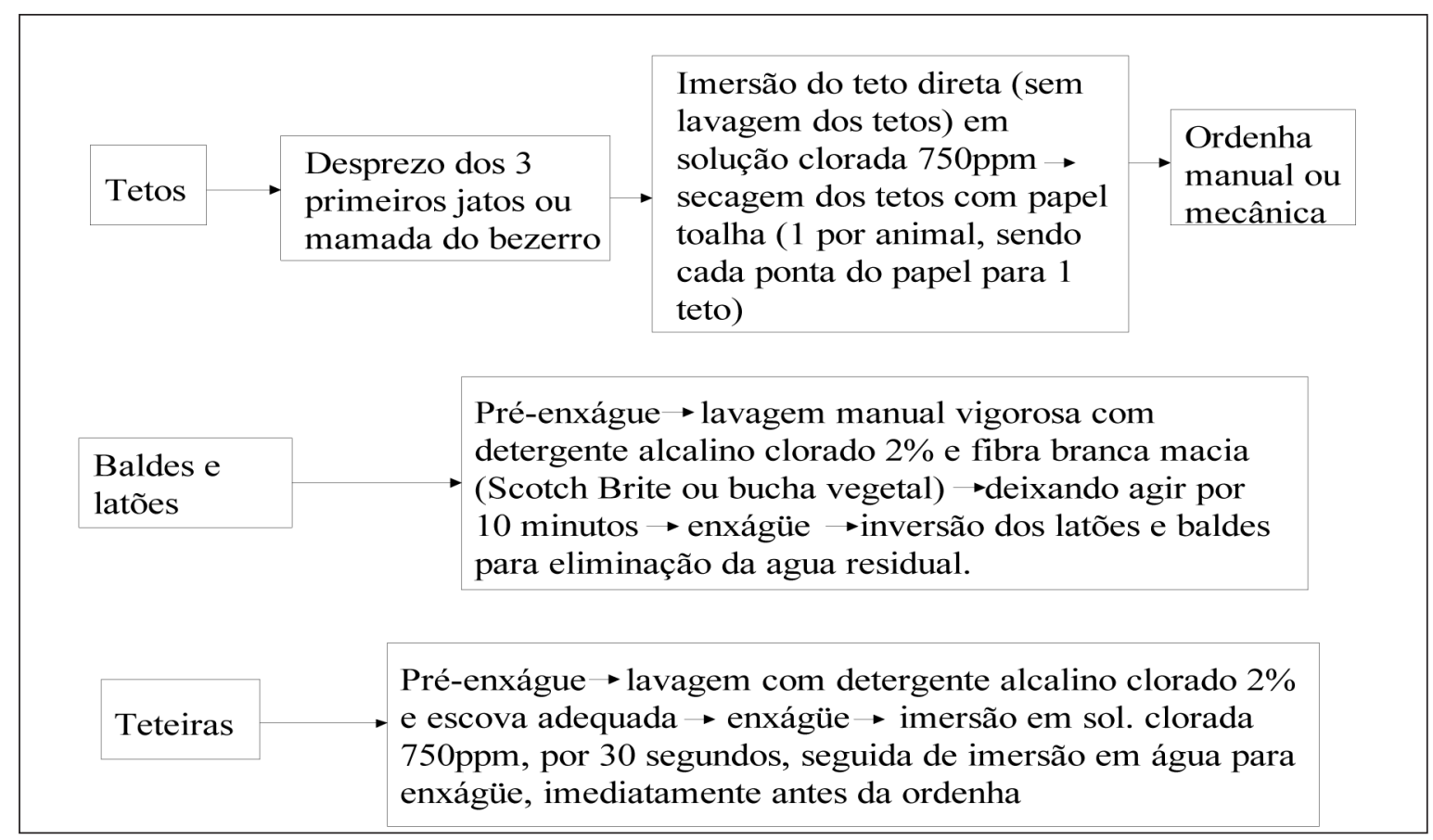

Foi desenvolvido um cinto suporte especial para o ordenhador a fim de facilitar o transporte da caneca de imersão de teto e das toalhas de papel, pois nas três propriedades que realizavam a ordenha em piquetes, não havia onde deixar estes materiais.
Após a otimização das práticas à realidade $\mathrm{e}$ rotina de cada propriedade estudada, estas foram demonstradas aos ordenhadores, que as realizaram durante a ordenha, sendo acompanhados pelos autores deste trabalho. 


\section{Avaliação das práticas}

Para avaliar a eficiência das práticas, compararam-se as médias de contagens de microrganismos aeróbios mesófilos (AM), coliformes a $30^{\circ} \mathrm{C}(\mathrm{CT})$, Escherichia coli (EC) e Estafilococos coagulase positivos (ECP), em cada ponto das quatro propriedades, antes e depois da realização dos procedimentos pelos produtores.

Os pontos amostrados foram: pool dos quatro tetos de quatro animais de cada propriedade, baldes, lateral e fundo dos latões, dois conjuntos de teteiras na propriedade com ordenha mecânica, três primeiros jatos, água residual dos latões e leite de conjunto.

Para realizar a amostragem da superfície de tetos, utensílios e equipamentos, utilizou-se swab (Quick $s w a b-3 \mathrm{M})$, que contém como meio de transporte o caldo Letheen, que tem por finalidade neutralizar a ação de resíduos de sanitizantes.

Foram utilizados moldes flexíveis de polietileno estéril para delimitação da área a ser amostrada, que era compatível com a área dos equipamentos, permitindo calcular a contaminação por $\mathrm{cm}^{2}$. Para tetos e teteiras a área amostrada foi de $3 \mathrm{~cm}^{2}$, para latões e baldes o molde foi de $100 \mathrm{~cm}^{2}$ (SANTANA et al., 2001). As amostras de leite de conjunto foram colhidas em bags estéreis, formando um pool dos latões ao final da ordenha, previamente homogeneizado.

Para a contagem de microrganismos AM, ECP, CT e EC dos pontos estudados utilizou-se Petrifilm ${ }^{\mathrm{TM}}$ AC, Petrifilm ${ }^{\mathrm{TM}}$ Staph Express e Petrifilm ${ }^{\mathrm{TM}}$ EC respectivamente conforme orientações do fabricante (3M Microbiology, St. Paul, MN, USA).

As amostras foram transportadas em recipientes isotérmicos com gelo reciclável. As análises foram realizadas (6 horas) após as colheitas, no Laboratório de Experimentação e Análises de Alimento (LEAAL) da Universidade Federal de Pernambuco, Recife/PE.

\section{Resultados e Discussão}

Os resultados das contagens médias de AM, CT, EC e ECP, obtidas de amostras de tetos, teteiras, latões, baldes, água residual dos latões e os três primeiros jatos, antes e depois da aplicação das diferentes práticas de higienização, são apresentados na (Tabela 1). A contaminação original em todos os pontos estudados se mostrou bastante alta e a implantação das práticas teve grande impacto na melhoria da qualidade do leite, nas propriedades estudadas.

O desprezo dos três primeiros jatos de cada teto antes da ordenha é importante para obtenção de leite com boa qualidade, uma vez que estes jatos apresentam altas contagens de microrganismos, principalmente de AM 3,8 x $10^{4} \mathrm{UFC} / \mathrm{mL}$ e ECP $1,6 \times 10^{4} \mathrm{UFC} / \mathrm{mL}$. Eliminar os três primeiros jatos diminui as contagens de AM e ECP também nos equipamentos e utensílios de ordenha, e também no leite final o que é bastante desejável se considerarmos que ECP é importante agente causador de mastite bovina. Além disso, o ECP é responsável por intoxicações alimentares pela produção de toxinas termoestáveis, que não são inativadas pela pasteurização, tratamento UHT ou pela desidratação para fabricação do leite em pó (FDA, 2007). Com a eliminação dos três primeiros jatos, considerou-se $100 \%$ a redução de microrganismos neste ponto, pois simplesmente deixaram de ser incorporados ao leite em sua totalidade.

Após a imersão dos tetos em solução clorada a 750ppm, a contagem média de microrganismos apresentou reduções de $91,3 \%$ para CT e $85,3 \%$ para ECP. Esta redução é importante, pois estes microrganismos são os principais causadores de mastite ambiental e contagiosa, respectivamente no rebanho leiteiro (SANTOS; FONSECA, 2007). Já para $\mathrm{AM}$ a redução foi de $87,3 \%$, o resultado foi satisfatório, embora um pouco inferior ao encontrado por Fagan et al. (2005), que obteve redução de $98,1 \%$. A menor redução ocorrida neste trabalho pode ser explicada pelas condições desfavoráveis 
encontradas em três das quatro propriedades estudadas, em que a ordenha e coleta de amostras eram realizadas no piquete, às vezes sob chuva, não em estábulo como no trabalho de Fagan et al. (2005). Segundo Santana et al. (2001), a incorporação de microrganismos aeróbios mesófilos ao leite, pelo teto mal higienizado, é de $86,0 \%$. Considerando a área média do teto de 50,8 $\mathrm{cm}^{2}$ (SANTOS; FONSECA, 2007), com a imersão direta dos tetos em solução clorada 750 ppm sem a lavagem, deixou de ser incorporado $1,2 \times 10^{7} \mathrm{UFC} /$ animal de AM no leite, com uma prática que pode ser realizada em qualquer situação de tecnificação das propriedades, porque não depende de disponibilidade de água no local de ordenha.

Tabela 1. Contagens médias em UFC $/ \mathrm{mL}$ ou $\mathrm{UFC} / \mathrm{cm}^{2}$ de aeróbios mesófilos (AM), coliformes a $30^{\circ} \mathrm{C}(\mathrm{CT})$, Escherichia coli (EC) e Estafilococos coagulase positivos (ECP), obtidas antes e após a implantação das práticas propostas, em diferentes pontos da ordenha de quatro propriedades leiteiras do agreste pernambucano, estudadas no período de agosto de 2005 a novembro de 2006.

\begin{tabular}{|c|c|c|c|c|c|c|c|c|}
\hline $\begin{array}{c}\text { Pontos } \\
\text { Amostrados }\end{array}$ & AM & $\begin{array}{c}\text { Redução } \\
\%\end{array}$ & CT & $\begin{array}{c}\text { Redução } \\
\%\end{array}$ & EC & $\begin{array}{c}\text { Redução } \\
\%\end{array}$ & ECP & $\begin{array}{c}\text { Redução } \\
\%\end{array}$ \\
\hline $\begin{array}{c}3 \text { primeiros } \\
\text { jatos }\end{array}$ & $3,8 \times 10^{4}$ & & $1,9 \times 10^{2}$ & & $5,2 \times 10^{1}$ & & $1,6 \times 10^{4}$ & \\
\hline $\begin{array}{c}\text { Desprezo } \\
\text { dos } 1^{\text {os jatos }}\end{array}$ & 0 & 100 & 0 & 100 & 0 & 100 & 0 & 100 \\
\hline Teto sujo & $7,9 \times 10^{4}$ & & $3,9 \times 10^{2}$ & & $1,8 \times 10^{2}$ & & $4,3 \times 10^{2}$ & \\
\hline $\begin{array}{c}\text { Teto após } \\
\text { pré-dipping* }\end{array}$ & $1,0 \times 10^{4}$ & 87,3 & $3,4 \times 10^{1}$ & 91,3 & $2,5 \times 10^{1}$ & 86,1 & $6,3 \times 10^{1}$ & 85,3 \\
\hline $\begin{array}{c}\text { Teteiras } \\
\text { antes }\end{array}$ & $2,3 \times 10^{5}$ & & $5,3 \times 10^{1}$ & & 3,3 & & $3,3 \times 10^{1}$ & \\
\hline $\begin{array}{c}\text { Teteiras após } \\
\text { as práticas }\end{array}$ & $9,2 \times 10^{2}$ & 99,6 & $3,3 \times 10^{-1}$ & 99,4 & 3,3 & $\mathbf{0}$ & 3,3 & 90,0 \\
\hline Latões antes & $2,2 \times 10^{5}$ & & $3,0 \times 10^{4}$ & & $1,0 \times 10^{2}$ & & 2,8 & \\
\hline $\begin{array}{l}\text { Latões após } \\
\text { as práticas }\end{array}$ & $5,6 \times 10^{3}$ & 97,4 & $1,6 \times 10^{1}$ & 99,9 & 2,0 & 98,0 & 0,2 & 92,9 \\
\hline Baldes antes & $2,2 \times 10^{3}$ & & $1,0 \times 10^{2}$ & & $1,0 \times 10^{2}$ & & $5,0 \times 10^{-2}$ & \\
\hline $\begin{array}{l}\text { Baldes após } \\
\text { as práticas }\end{array}$ & $1,7 \times 10^{1}$ & 99,2 & $1,0 \times 10^{-2}$ & 99,9 & $1,0 \times 10^{-2}$ & 99,9 & $1,0 \times 10^{-2}$ & 80,0 \\
\hline $\begin{array}{c}\text { Água } \\
\text { residual } \\
\text { dos latões }\end{array}$ & $9,8 \times 10^{7}$ & & $4,2 \times 10^{4}$ & & $1,1 \times 10^{4}$ & & $1,0 \times 10^{2}$ & \\
\hline $\begin{array}{l}\text { Inversão dos } \\
\text { latões }\end{array}$ & 0 & 100 & 0 & 100 & 0 & 100 & 0 & 100 \\
\hline
\end{tabular}

* imersão em solução de cloro a 750ppm

A propriedade $\mathrm{P} 1$ realizava a imersão dos tetos em solução iodada, imediatamente antes e após a ordenha, mas em concentrações abaixo da recomendada por Santos e Fonseca (2007), mostrando que se estas práticas não forem corretamente realizadas não ocorrerá impacto na melhoria da qualidade do leite.
O cinto para ordenha, com suporte para a caneca de imersão e as toalhas de papel, viabilizou a prática do pré-dipping no piquete, já que o ordenhador não tinha local para colocá-los. Este aparato possibilitou que estes materiais ficassem ao alcance dos ordenhadores, facilitando a execução das práticas. 
As teteiras após a higienização recomendada apresentaram reduções nas contaminações de 99,6\%, chegando a $3,3 \mathrm{UFC} / \mathrm{cm}^{2}$ para AM. A redução foi de $99,4 \%$ para $\mathrm{CT}$ e $90,0 \%$ para ECP. Apenas para EC não ocorreu redução, mas isso pode ser explicado pela baixa contagem inicial média deste microrganismo 3,3 $\mathrm{UFC} / \mathrm{cm}^{2}$ (Tabela 1). A associação da prática de higienização das teteiras no início da ordenha e o pré-dipping, que reduzindo fortemente a contaminação dos tetos, reduz também a recontaminação das teteiras durante a ordenha, mostrou grande impacto na qualidade do leite, além de colaborar no controle da mastite bovina. Ficou demonstrado que é imprescindível a higienização adequada das teteiras no início da ordenha e a imersão dos tetos em solução clorada a 750 ppm para evitar sua recontaminação.

Os latões e baldes apresentaram reduções de $80,0 \%$ a $99,9 \%$ na contagem dos diversos microrganismos pesquisados, após a lavagem vigorosa com fibra macia e detergente alcalino clorado 2\%. Dados semelhantes foram encontrados por Fagan et al. (2005) que obtiveram redução de 99,9\%, para aeróbios mesófilos. A ação química deste detergente remove resíduos de gorduras e proteínas do leite, permitindo melhor ação do cloro (ANDRADE; MACÊDO, 1996). Já a ação mecânica é importante, pois ocorre aumento da resistência dos microrganismos ao cloro quando estes ficam aderidos à superfície, e isso constitui o primeiro mecanismo de sobrevivência das bactérias à ação dos desinfetantes. Bactérias heterotróficas quando estão aderidas aumentam a resistência aos desinfetantes em 2.400 a 3.000 vezes (LECHEVALLIER; CAWTHON; LEE, 1988).

Foi encontrado em média $105 \mathrm{~mL}$ de água residual nos latões. A contagem média de aeróbios mesófilos foi de $9,8 \times 10^{7} \mathrm{UFC} / \mathrm{mL}$ de água. Portanto, por latão, seriam incorporados $1,0 \times 10^{10} \mathrm{UFC}$ de aeróbios mesófilos ao leite. Contagens de 3,6 x $10^{8} \mathrm{UFC} / \mathrm{mL}$ foram encontradas por Fagan et al. (2005). Com a simples prática de inverter os latões, em local limpo seco e afastado do solo, elimina-se totalmente a água residual, e por isso considerouse como $100 \%$ a redução dos microrganismos neste ponto.

Para avaliação do impacto conjunto das práticas no leite final, os resultados obtidos nas propriedades P1 e P3 antes da realização das práticas tiveram que ser descartados, porque os proprietários relataram adicionar peróxido de hidrogênio ao produto no final da ordenha, impedindo a comparação. O peróxido de hidrogênio é uma substância com ação bactericida e/ou bacteriostática, dependendo da concentração, da microbiota presente e do produto em que é utilizado. Segundo a legislação brasileira, é proibida a adição de peróxido de hidrogênio em leite e derivados para preservá-los por maior tempo, pois pode resultar em danos à saúde dos consumidores, dentre outros problemas (BRASIL, 2002). Entretanto, por ser um conservante de baixo custo e eficiente, a água oxigenada é ilegalmente utilizada no leite e seus derivados. Pudemos constatar que esta é uma prática disseminada no agreste pernambucano e está relacionada com a má qualidade microbiana do leite, quanto à dificuldade de conservação e escoamento da produção. Deste modo foram considerados os resultados de duas propriedades.

A (Tabela 2) mostra a contagem média de AM, CT, EC e ECP do leite final das propriedades após a implantação das práticas propostas. 
Tabela 2. Contagem média de aeróbios mesófilos (AM), coliformes a $30^{\circ} \mathrm{C}(\mathrm{CT})$, E. coli (EC) e Estafilococos coagulase positivos (ECP) do leite do pool de latões ao final da ordenha antes e após a implantação das práticas propostas, em duas propriedades leiteiras do agreste pernambucano, estudadas no período de agosto de 2005 a novembro de 2006.

\begin{tabular}{ccccccccc}
\hline $\begin{array}{c}\text { Contagem } \\
\mathbf{U F C} / \mathbf{m L}\end{array}$ & $\mathbf{A M}$ & $\begin{array}{c}\text { Redução } \\
\mathbf{\%}\end{array}$ & $\mathbf{C T}$ & $\begin{array}{c}\text { Redução } \\
\mathbf{\%}\end{array}$ & $\mathbf{E C}$ & $\begin{array}{c}\text { Redução } \\
\mathbf{\%}\end{array}$ & $\mathbf{E C P}$ & $\begin{array}{c}\text { Redução } \\
\mathbf{\%}\end{array}$ \\
\hline $\begin{array}{c}\text { Antes das } \\
\text { práticas }\end{array}$ & $1,3 \times 10^{8}$ & & $1,5 \times 10^{5}$ & & $3,5 \times 10^{4}$ & & $1,7 \times 10^{3}$ & \\
$\begin{array}{c}\text { Após as } \\
\text { práticas }\end{array}$ & $1,8 \times 10^{4}$ & $\mathbf{9 9 , 9}$ & $1,2 \times 10^{3}$ & $\mathbf{9 9 , 2}$ & $7,0 \times 10^{2}$ & $\mathbf{9 8 , 0}$ & $6,9 \times 10^{2}$ & $\mathbf{5 9 , 4}$ \\
\hline
\end{tabular}

A implantação das práticas propostas levou a uma redução média de $99,9 \%$ de microrganismos AM no leite final. O leite da última ordenha anterior a das práticas, apresentou a contagem de $1,3 \times 10^{8}$ $\mathrm{UFC} / \mathrm{mL}$, este leite estava fora dos padrões mínimos de qualidade estipulados pela IN 51, que determina máximo de $1,0 \times 10^{6} \mathrm{UFC} / \mathrm{mL}$ de AM (BRASIL, 2002). Após a implantação das práticas de desprezo dos três primeiros jatos de leite, imersão do teto em solução clorada 750 ppm em caneca sem refluxo, higienização vigorosa de latões e baldes com detergente alcalino clorado $2 \%$, a contagem de mesófilos foi de $1,8 \times 10^{4} \mathrm{UFC} / \mathrm{mL}$, ou seja, este leite se enquadra nos parâmetros da IN 51 e apresenta qualidade microbiológica muito boa.

As reduções para CT, EC e ECP, demonstram que estas práticas são eficientes para todos os microrganismos estudados e necessárias para obtenção de um leite de qualidade.

Após os trabalhos nas propriedades foram colhidos depoimentos dos proprietários e ordenhadores, os quais relataram facilidade na implantação das boas práticas e poucas mudanças na rotina de ordenha, fatores importantes para que as práticas sejam realmente incorporadas.

\section{Conclusões}

As boas práticas de ordenha demonstraram ser suficientes para adequar o leite produzido aos parâmetros estabelecidos pela IN 51 .
As práticas de ordenha recomendadas são simples, eficientes, de fácil incorporação na rotina de ordenha em qualquer situação de tecnificação das propriedades e não requerem gastos com instalações.

\section{Agradecimentos}

Este trabalho faz parte do projeto "Produção de leite com qualidade e segurança a partir da implantação de Boas Práticas na Produção leiteira em Pernambuco" e tem o apoio financeiro da FINEP.

\section{Referências}

ANDRADE, N. J.; MACÊDO, J. A. B. Higienização na indústria de alimentos. São Paulo: Varela, 1996.

BELMONTE, E. A.; LAGO, N. C. M. R. Pesquisa de microrganismos indicadores em leite pasteurizado integral comercializado nas cidades de Ribeirão Preto e Sertãozinho, SP. In: CONGRESSO BRASILEIRO DE QUALIDADE DO LEITE, 1., 2004, Passo Fundo. Anais... Passo Fundo: [s.n.], 2004. CD-ROM.

BELOTI, V.; BARROS, M. A.; FREIRE, R. J.; NAVARRO, I. T.; SOUZA, J. A.; NERO, L. A. Evaluation of Physicalchemical and microbiological characteristics of pasteurized milk type commercialized in Londrina city, Paraná, Brazil. Epidemiologie et Sante Animale, France, v. 31/32, n. 4, p. 50-51, 1997.

BELOTI, V.; TAMANINI, R.; CAVALETTI, L. C. S.; MAGNANI, D. F.; MONTEIRO, A. A.; BARROS, M. A. F.; MATTOS, M. R.; MORAES, L. B.; FAGAN, E. P.; SILVA, W. P.; PIRES E. M. F. Obtenção de leite com qualidade através da implantação de boas práticas na ordenha, em quaisquer condições de produção. 
In: CONGRESSO BRASILEIRO DE MEDICINA VETERINÁRIA, 17., 2006, Gramado. Anais... Gramado: UFPL, 2006. CD-ROM.

BRASIL. Ministério da Agricultura, Pecuária e Abastecimento. Instrução Normativa n.51 de 18 de setembro de 2002. Regulamento Técnico de Produção, Identidade e Qualidade de Leite Tipo A, Tipo B, Tipo $\mathrm{C}$ e Cru refrigerado. Diário Oficial [da] República Federativa do Brasil, Brasília, 29 set. 2002. Seção 1, p. 13.

CATÃO, R. M. R.; CEBALlOS, B. S. O. Listeria spp., coliformes totais e fecais e E.Coli no leite cru e pasteurizado de uma indústria de laticínios, no Estado da Paraíba (Brasil). Ciência e Tecnologia de Alimentos, Campinas, v. 21, n. 3, p. 281-287, set./dez. 2001.

CONAB. Conselho Nacional de Abastecimento. Conjuntura regional Pernambuco 2004. 2004. Disponível em: <http:/www.conab.gov.br/download/ sureg/PE/ conjuntura01.pdf $>$. Acesso em: 18 fev. 2008.

FAGAN, E. P.; BELOTI, V.; BARROS, M. F.; MULLER, E. E.; NERO, L. A.; SANTANA, E. H. W.; MAGNANI, D. F.; VACARELLI, E. R.; SILVA, L. C.; PEREIRA, M. S. Evaluation and implementation of good pratices in main points of microbiological contamination in milk production. Semina: Ciências Agrárias, Londrina, v. 26, n. 1, p. 83-92, jan./mar. 2005.

FDA. Food and Drug Administration. Center for safety and applied nutrition. Bacterial pathogens growth and inativation. 3. ed. jun. 2007. Disponível em: <http:// www.seafood.ucdavis.edu/HACCP/compendium/ chapt19.htm>. Acesso em: 19 jun. 2007.

FIGUEIROA, J. G. O sinal verde para a reestruturação da agroindústria do leite no agreste. 2006. Disponível em:<http: / www.agronline.com.br/ artigos/ artigos. php?id=240>. Acesso em: 18 fev. 2006.

FRANCO, B. D. G.; LANDGRAF, M. Microbiologia dos alimentos. 2. ed. São Paulo: Atheneu, 2008.

LECHEVALLIER, M. W.; CAWTHON, C. D.; LEE, R. G. Factors promoting survival of bacteria in chlorinated water supplies. Applied Environmental Microbiology, v. 3, n. 54, p. 649-654.1988.
MARTINS, S. C. S.; ALBUQUERQUE, L. M. B. Qualidade do leite pasteurizado tipo $\mathrm{C}$ comercializado no município de Fortaleza. Bactérias multiresistentes a antibióticos. Higiene Alimentar, São Paulo, v. 13, n. 59, p. 39-42, jan./fev. 1999.

MONTEIRO, A. M.; TAMANINI, R.; CAVALETTI, L. C. S.; MATTOS, M. R.; MAGNANI, F. M.; OVIDIO, L.; NERO, L. A.; BARROS, M. A.; PIRES, E. M. F.; PAQUEREAU, B. P. D.; BELOTI, V. Características da produção leiteira da região do agreste do Estado de Pernambuco, Brasil. Semina: Ciências Agrárias, Londrina, v. 28, n. 4, p .665-674, out./dez. 2007.

NELSON, J. H. An overview of good manufacturing pratice. Bulletin of the International Dairy Federacion, Brussels, v. 276, p. 10-11, 1992.

NERO, L. A.; MATTOS, M. R.; BELOTI, V.; BARROS, M. A.; PINTO, P. A.. N.; ANDRADE, N. J.; SILVA, N. J.; FRANCO, D. G. M. Leite cru de quatro regiões leiteiras brasileiras: perspectivas de atendimento dos requisitos microbiológicos estabelecidos pela Instrução Normativa 51. Ciência e Tecnologia de Alimentos, Campinas, v. 25, n. 1, p. 191-195, jan./mar. 2005.

PADILHA, M. R. F.; FERNANDES, Z. F.; LEAL, T. C. A. L.; LEAL, N. C.; ALMEIDA, A. M. P. A. Pesquisa de bactérias patogênicas em leite pasteurizado tipo $\mathrm{C}$ comercializado na cidade do Recife, Pernambuco, Brasil. Sociedade Brasileira de Medicina Tropical, Uberaba, v. 34, n. 2, p. 167-171, mar./abr. 2001.

SANTANA, E. H. W.; BELOTI, V.; BARROS, M. A. F.; MORAES, L. B.; GUSMÃO, V. V.; PEREIRA, M. S. Milk contaminação do leite em diferentes pontos do processo de produção: microrganismos aeróbios mesófilos e psicrotróficos. Semina: Ciências Agrárias, Londrina, v. 22, n. 2, p. 145-154, jul./dez. 2001.

SANTOS, M. V.; FONSECA, L. F. L. Estratégias para controle de mastite e melhoria da qualidade do leite. São Paulo: Manole, 2007.

SPRRA. Secretaria de Produção Rural e Reforma Agrária. Programa leite de Pernambuco. 2007. Disponível em: $<$ http://www.producaorural.pe.gov.br/leite/ o_programa. htm>. Acesso em: 14 set. 2007. 
